\title{
The Interdisciplinary Lesson Plan of Interdisciplinary Teaching in Science-Based Technology School
}

\author{
Kanphitcha Kodkanon and Pichet Pinit
}

\begin{abstract}
This paper focuses on how to create an interdisciplinary lesson plan (ILP) through project-based learning. The ILP applies to scientists, technicians, and mechanics in science-based technology schools. Characteristics of the ILP integrate science, engineering, english, mathmatics, and Information Technology. The ILP is developed by an interdisciplinary teaching team include teachers from various disciplines. This paper describes the five states of ILP creation: establishment of an interdisciplinary core; course mapping and performance map; identifying the essential question and key question; establish student assessments; and write lesson plans. ILP is based on real-life pedagogical problems using $21^{\text {st }}$ century skills.
\end{abstract}

Index Terms-Intercultural education, interdisciplinary lesson plan, team-teaching, science-based technology.

\section{INTRODUCTION}

The interdisciplinary lesson plan (ILP) prepares for mechanics program in science-based technology school. Previously, students studying separate subjects that are independent and disconnected from each other. Teachers plan lesson by the individual. The main point of each semester, students create an invention or innovation in a project course through project-based learning process [1]. The creation of the invention must relate to various knowledge and skills. Interdisciplinary Team Teaching (ITT) is a good choice to impact students. Team teaching results in significant gains in student attitude and modes of thinking. [2] In the interdisciplinary team approach, teachers of several different subjects were assigned one group of students and encouraged to correlate at least some of their teachings. [3]. We decide to develop an interdisciplinary lesson plan thought, integrating the disciplines to the interdisciplinary unit. Interdisciplinary units are generally given long periods during the school day to research areas of interest to them. They were guided and supported by the teacher, but the focus is on the student being an active learner. Assessment tends to individualized. May take the form of a portfolio of work completed by the individual. [4] Each semester students must join in one Interdisciplinary unit thought the sub-theme. Interdisciplinary unit brings together academic and technical subject according students' learning skill level. We designed context of leaning under the main theme "we are going to part

Manuscript received May 3, 2014; revised July 7, 2014.

Kanphitcha Kodkanon is with Learning Innovation and Technology, Faculty Industrial Education and Technology, King Mongkut's University of Technology Thonburi, Thailand (e-mail: 54501801@kmutt.ac.th).

Pichet Pinit is with Department of Mechanical Technology Education, Faculty Industrial Education and Technology, King Mongkut's University of Technology Thonburi, Thailand (e-mail: Pichet.pin@kmutt.ac.th). of the green world". Sub-themes on each semester are green energy, green machine, green team-mate, green society, and green world.

\section{LEARNING ORGANIZING FOR SCIENCE BASED TECHNOLOGY SCHOOL (SBTS) BASED ON PROJECT BASED LEARNING}

\section{A. What Are SBTS?}

Science based Technology school (SBTS) is a vocational college which specialized program focus on teaching students to be innovators who specify scientific and professional technicians through project-based learning. Normally, Thailand vocational educations focus on producing skilled craftsmen and technicians who work on technology users more than technology inventor. Then curriculums Certificate for traditional programs of Vocational Education do not focus on science. When these students study in higher education, they are explore to insufficient of science academic which necessary in higher education. The Vocational Education Commission (VEC) joined hands with the National Science Technology and Innovation Policy Committee (NSTIC) to form SBTS The goal of project was to develop the human resources among talented children in response to the needs of the Thai economy and society [5].

\section{B. Structure of an Interdisciplinary Lesson Plan (ILP)}

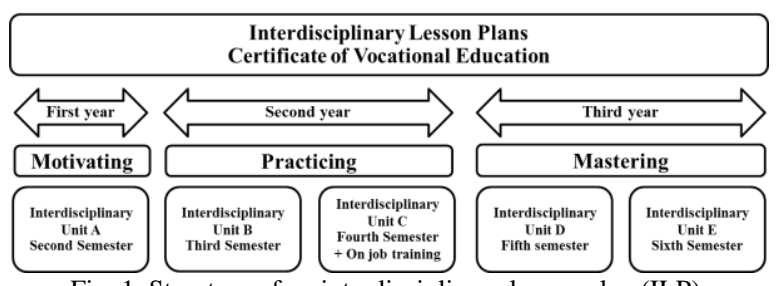

Fig. 1. Structure of an interdisciplinary lesson plan (ILP).

The curriculum of the Certificate of Vocational Education in SBTS features the basic knowledge of science and mathematics to the high school level, and at the same time has vocational skills at the same level as vocational education. The teaching process integrates eight groups including: 1) English; 2) Mathematics; 3) Science; 4) Social, Religious, Cultural; 5) Physical health; 6) Art; 7) Career; and, 8) Foreign language. [6] The academic year divides into two semesters. A summer semester depends on requirement of the respective college. Each semester consists of eighteen weeks. We adjust learning style of integrated subjects by interdisciplinary team teaching. We create an interdisciplinary lesson plan (ILP). Characteristics of ILP integrate mechanics engineer, science, mathematics, English, 
and information technology. ILP consists of five interdisciplinary units. The structure of an ILP is displayed in Fig. 1.

\section{Learners' Skills Level}

We organize learners' skill levels into three levels, such as motivating, practicing, and mastering. The first academic year aims at motivating students to become innovators. In second semester of the first academic year we start teaching process through project-based learning by ILP at this time on interdisciplinary unit A. The unit theme of Interdisciplinary unit A to motivate student to create an invention or innovation in the first project through project-based learning. The first students' project should be small and simple. Students can make individual or small group attribution depending on the complexity of the invention and the students' interest. The second academic year aims at practicing. During the third semester, students must participate in interdisciplinary units B and create a second project. The second students' project is similar to the first project, but require more coordination between projects depending on the complexity of the problem. Fourth semester, students participate in interdisciplinary units $\mathrm{C}$, interdisciplinary units $\mathrm{C}$ including internships with the company during the summer semester. The third student's project must further develop their projects through cooperation with the company. This year we focused on increased technical skills of learners. Students' project should contribute to the community. The third year academic aims at mastering the stream focusing on innovative perspectives. Students must participate with couple interdisciplinary units. Students must create a fifth project through interdisciplinary units $\mathrm{D}$ and sixth project through interdisciplinary units E during their field year. The fifth project is similar to the previous project, and the sixth project is a special project. These project students integrate knowledge and previous experience to create projects. Students can create projects through integrated previous invention to new inventions.

\section{Project Based Larning Pocess}

King Mongkut's University of Technology Thonburi [7], [8] suggests project-based learning follows a five-step implementation process exploring the ideas, reviewing the possibilities, selecting the topic, producing and testing, and presenting and selling. The team must plan ILP support project-based learning

The first step is exploring the ideas. This step emphasizes the creation and development of student creative thinking. Facilitators should encourage students to use creative thinking through brainstorming to select on "Interest Topic". This step usually requires a couple weeks.

The second step is reviewing the possibilities. This step requires students to search theory and principle in order to the support each topic selected in the first step. Students search various data sources such as books, articles, journals, and, the internet. The facilitator introduces various data sources, monitors data and information. This step usually requires a couple weeks.

The third step is selecting the topic. In this step students select a topic to study through brainstorming in groups.
Facilitators contribute to this approach to learning by describing the innovation and making the problem real and compelling for students. The facilitators also prepare project advisors for the group. Advisors relate their expert skills to project students. Afterward, students define the title's project and select the real problem. The project advisor then consults with the groups to write their proposal suitable for presentation. The groups present proposal to an evaluator. The project facilitator and project advisor should participate and the evaluator will give advice and provide feedback for developing the invention. This step should be done before the fifth week on school time.

The fourth step is producing and testing. Students present the framework of the project operation and action plan. Students must consult with the advisor to establish the project's progress. The advisor must participate and monitor the possibilities and interest of the project's framework. Students create an invention or innovation and an action plan schedule. In this step students must use skills to create an invention or innovation. The advisor should consult about skills with students and control their work. This step usually requires minimizing the eighth week and 10 weeks for maximum.

The fifth step is presenting and selling. This step consists of the students' presentation. The students make a presentation through media or tools to present prominent points and product values. Afterward, students must present to the evaluator. This step should proceed a couple of weeks before school close. Make sure students can rectify project follows comment from the evaluator.

\section{E. Interdisciplinary Team}

The Interdisciplinary team must be identified and justified. The Interdisciplinary team depends on the teacher who response course in each semester. The team need to be expert and flexible teachers. [9] The team need to be able to communicate complex ideas from multiple disciplines at the level appropriate for students. The Interdisciplinary team consists of Team Leaders who response interdisciplinary core on each semester. Team Leaders takes roles to orchestrate team activity, schedule integrated unit meetings and evaluates the progress of the unit, maintain team record, and serve as a communication link with the rest of the team. Before the project, Team Leaders takes responsibility for coordinator of the team when creating an interdisciplinary lesson plan (ILP). During the project takes role facilitator on project-based learning process. After the project, Team leader's responsibilities make sure the project documentation is complete and available. All Team Members who responsed attend a meeting set by the team leader in collaboration with in Interdisciplinary units an interdisciplinary lesson plan (ILP), Team Members usually consist of the Thai Language teacher, the English Language teacher,the Mathematics teacher, the Science teacher, and the vocational teacher. Before the project, Team members shares knowledge and generate integrates unit when creates an interdisciplinary lesson plan (ILP). During the project, takes roles Expect content especially Language teachers and Mathematics teacher on project-based learning process. As for a Science teacher and vocational teacher takes role as facilitator and adviser on project-based learning process. 


\section{FIVE SAGES OF IPL CEATION}

When we launch Interdisciplinary team in SBTS. ILP to occur on second steps of Model Interdisciplinary Team Teaching. [8] Five stages of IPL creation are the establishment of an interdisciplinary core; course mapping and performance map; identifying the essential question and key question; establish student assessments; and write lesson plans. IPL is based on real-life pedagogical problems using 21 st century skills.

\section{A. First Stage: Establishment of an Interdisciplinary Core}

The interdisciplinary core is interdisciplinary subjects offering the opportunity to explore important ideas that challenge students to create an invention on a theme. However SBTS curriculum has a structure program for each semester which design base of knowledge and skills. Team should analyze Interdisciplinary core by integrating the disciplines which two courses to be Interdisciplinary core. The main point when team chooses a course to interdisciplinary core. Interdisciplinary core should be a course which part of core vocational course or specialized vocational courses because we focus on professional technical skills. Collaboration with a course in a project group course because we need student innovation.

Interdisciplinary core should :

1) Provide for high-quality student projects;

2) Link academic and technical content and skill;

3) Help students and teachers make connections across academic disciplines. Concurrence with Theme; and

4) Support Learners' skills level each year.

The sub-theme for this semester is green energy. Team creates ILP as: Collect Energy and Environment course and Project I course to be interdisciplinary core. After team collects interdisciplinary core therefor teacher who response these courses take roles team leader. A team leader's responsibility to create and maintain channels that enable Team members to do their work. [10] Generate interdisciplinary core discipline by making connection across academic disciples to scope of learning. Afterwards, team must identify learning goals, concepts, objectives, competencies for the particular discipline through creating learning goals map. Draw a two-column grid on the paper. Enter each course of the discipline title in the left column and the corresponding learning goals in the right column. Allow for questions, clarification, and discussion, Clarify common core learning goals. A team leader must take roles coordinator and handle of procedure. The team member should be participating. Specially, interdisciplinary units c including internships with the company during summer semester. The first step is getting to know local industry or company partners. Partners are invaluable in helping to identify authentic application for academic and technical course content. Evaluate the quality of students' work

\section{B. Second Stage: Course Mapping and Performance Map}

When Interdisciplinary core of ILP is complete. Teams create an integrated unit through technique of connections planning wheels [11]. The steps are following

1) Draw a concept wheel with a circle at the center and an arm for each discipline that you intend to consider.
2) Next, place the organizing center that Interdisciplinary core in the hub of the wheel. Within each subject area. Identify concepts to arm of the content wheel. Develop a map that connects the concepts. The concept map will help teachers visualize more clearly the way in which separate subjects can converge on Interdisciplinary core. Connections planning wheels is displayed in Fig. 2.

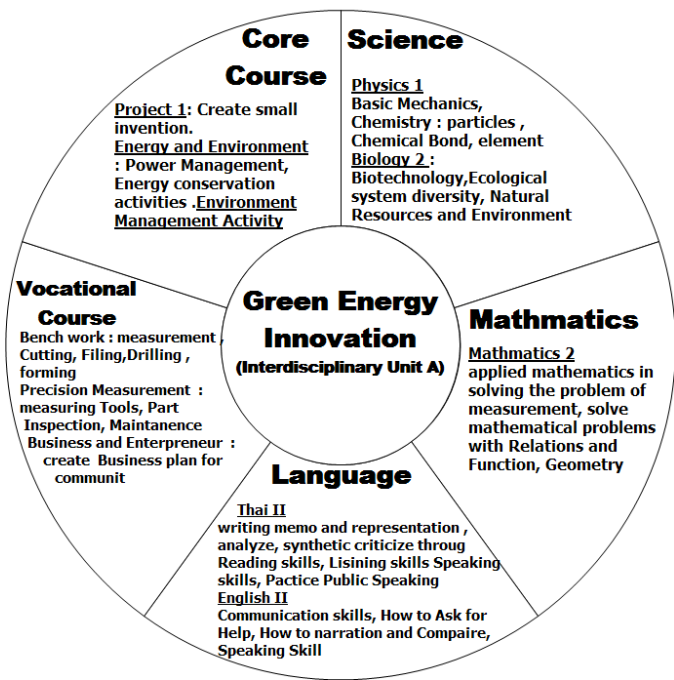

Fig. 2. Connections planning wheels.

3) Team members created a performance map. Individually, teachers should map out the existing scope and sequence of the topic covered the their course. Next, teachers should align their course outline topics. Finally the teachers unpack topic and competency by translation to performance that students are expected to master and demonstrate. The objective is to set priorities for what students need to know and be able to do. Performance map provides a useful tool for looking at your own class and the way in which the relevancy of the topics you teach and students' motivation. These maps also provide a tool for finding natural connections from which build the project. [4] After the individually performance map are complete, the team should share the map through group meetings.

4) Team staff must decide the topic of the unit support Interdisciplinary core. The integrated unit is designed to place important academic content in the context of meaningful, Real-world problems that arouse students' curiosity. Team should adhere closely to the existing performance map when choosing a topic for the unit. The topic is to look at important topics, standards, and performances across academic disciplines. Look for connections between the content that students are learning and skills that student are expected to master.

Each member must propose knowledge and skills to engage each lesson under their course outline. Afterward unpack competency into perform that students are expected to master and demonstrate. Team should verify the $21^{\text {st }}$ century skills and students' worksheet and students' invention. Team must place importance on Learners' skills. This process may be through brainstorms or discussions in a group meeting. In a group team member should present a brief overview of their course to the rest of the team and a detailed description of the performance measures. Having the 
team leader begin this discussion helps a team member start thinking about integrating topics that may be relevant to the topics and concept they cover. A specific example of an integrated approach was found in a school were working on a science-based project about the 'health' of a local lake. During Science, students learned about water quality and aquifers. In society and environment students examined human development in their local region and the impact that has on the lake. In English they participated in an extended hypothetical debate and role play of different advocate groups about the development of the surrounding environment and the recreation that should be allowed in the lake. In this way, more connectedness and application of knowledge to the issue of concern. [5]

For example, reference to wind power (described as part of interdisciplinary units A) may lead a technical teacher to think about wind turbine construction or help a mathematics teacher to think about measure of power. For vocational who response business and entrepreneur course to think about the business plan of wind energy for local communities. For Thai language to think about public speaking or debate. English to think about reading comprehension of the article. At this time, team members can also identify concepts in their disciplines. All team staff is familiar with the content and performance measure of each integrates topic. It is time to brainstorm the various connections that can be made across the academic course linking them to interdisciplinary core.

A good topic will have the following characteristics :

- Is relevant to students' lives and interests;

- Reinforce content standards and skills;

- Is general enough to include all major academic disciplines;

- Cuts across all disciplines and may be addressed from various disciplinary perspectives;

- Lends on with student investigation and research; and

- Can be linked to community issue and needs.

\section{Third Stage: Identifying the Essential Question and Key Question}

The essential question is a fundamental query that directs and drives the search for understanding across all participating subject areas. The essential question is central to the design of the unit that address authentic concerns. The question challenges student to solve real-world problem and applies to more than one discipline, and full understanding requires learning in more than one discipline. When creating the Essential question use the following guidelines: 1) Essential questions are provoked, They must sustain students' interest and challenge students to go beyond superficialities. 2) The essential question is open-ended, but also feasible. They do not to lead to easy answer. Instead Essential question engages students in higher-level thinking. Make sure the question cannot be answered with a simple "yes" or "no". 3) The essential question is challenging. They encourage students to confront difficult issues and try out unfamiliar behaviors. These are example that students addressed through units in Interdisclipnary units A.

- How can we survive in a world without electric when we ran out the primary electric source?

- What is energy, where do we find it, how does is change from one form to another, and how does it affect our everyday lives?

- Why is it important for us to conserve energy and consider alternative energy sources?

- How can we balance technology, growth, and preserving the environment?

Afterward, the team must unpacking essential question in two key questions which subject specifically. Key question focus attention on an issue that is authentic to a specific academic or technical discipline.

\section{Fourth Stage: Establish Student Assessments}

Indisciplinary units offer teachers many opportunities to move beyond traditional tests. Teams can design engaging and challenging performance formative and summative student assessments that will match their objectives. when students completely engage in Indisciplinary units students create culminating products. The summative evaluation is an opportunity for students to display their higher-order thinking skills, problem-solving abilities, effective teamwork, written and oral communication skills, and ability to integrate and apply knowledge. And then design the formative evaluation, Teacher can use student work products for feedback and assessments and also avoid having to much of semester's final grade. Student work products demonstrate students' learning.

The formative evaluation need to meet the evaluation purpose. This depends on the nature of each unit and can include various assessments, such as invention assessment, team assessment, individual assessment, and behavior observation assessment.. Example of student work products for formative evaluation are: 1) A selection of readings that individuals or teams recommend for team; 2) A research paper on one Key questions addressed in a specific discipline; and 3) A set of drawing, designs, graphic representation that are relate to the essential question or one of key question.

\section{E. Fifth Stage: Write Lesson Plans}

The interdisciplinary team must decide on the final activities and coordinate times and dates for activities. The Indisciplinary unit open to student input. The more students can generate their own sub-themes and project ideas, the greater the chance for student engagement and learning. These stages teams start writing lesson plans of Indisciplinary units. Each lesson plan should address one or more of the key question relevant to integrated units. Lesson plans should include specific activities supporting each lesson. Characteristic of activity should be:

- Integrate knowledge and skills from various team members;

- Link activity through students' worksheet;

- Monitor and collect students' worksheet by expertise of teachers;

- Collaboration among team through team teaching model; and

- Real-Life problem involving the discharge of 21 st century skills.

A specific example of the interdisciplinary units A for motivating students, we generating biomass energy lesson. Generate first activity to the assignment student's to search information from internet. Teams assign Information 
Technology take responsibility to coach students, The science teacher takes responsibility to collect students' worksheet and grade to students. Second Activity is creating bio-diesel. The chemistry teacher takes responsibility to coach lab activity, collect students' worksheet, and grade to students. After complete this activity, students must choose own procedure for creating bio-diesel. To continue next activity, third activity is creating bio-diesel inventor. The technical teacher takes responsibility to coach students to create. Students must create invention support own procedure. Fourth activity is writing a research paper. The thai language teacher takes responsibility for coach student to write papers. When collect students' worksheet the thai language teacher responsibility to collect writing skills, the chemistry teacher responsibility to collect accuracy content. The two teacher grade together.

\section{CONCLUSION}

Interdisciplinary lesson plan (ILP) have certain advantage over traditional lesson plan. The strengths of teachers from various major can be highlighted to help the students. Successful of ILP depend on integrating the disciplines which need a strong team participate. Interdisciplinary unit must support real-life problem and students' interest. ILP design integrate various subjects to be holistic, reduce duplication of content, reduce class time for increased learning beyond the classroom.

\section{ACKNOWLEDGMENT}

This work was supported in part by the Faculty Industrial Education and Technology, King Mongkut's University of Technology Thonburi.

\section{REFERENCES}

[1] P. Nownaisin, N. Hongkrailert, K. Chancharoen, and K. Chomsuwan "The current state and problems of educational management in the science-based technology school (SBTS) of Thailand," in Proc. PICMET '11: Technology Management in the Energy-Smart World (PICMET), 2011, pp. 1168-1170.
[2] D. M. Carpenter II, L. Crawford, and R. Walden, "Testing the efficacy of team teaching," Learning Environment Research, vol. 10, pp. 53-65, 2007.

[3] D. J Thapwongse, "Report of a national pilot project school science-based technology school 1 , project-based learning process. Lessons learned and Policy Recommendations (Phase 1)," Thailand: Science-Based Technology School, 2008, Phanthong Chonbubi.

[4] M. Clayton, Designing Multidisciplinary Integrated Curriculum Units, School of engineering and Science, Sacramento City Unified District. CA, USA, 2010, pp-15-40.

[5] G. Venville, "Disciplinary versus integrated curriculum: The challenge for school science," in the Second International Handbook of Science Education, B. Fraser, K. Tobin, and C. McRobbie, Ed., Springer, 2010.

[6] Office of Vocational Education Commission, Curriculum of Certificate of Vocational Education Industrial Based Program for SBTS Project, Bangkok, 2009.

[7] King Mongkut's University of Technology Thonburi, Handbook for Training SBTS's Teacher on Project-based Learning, Bangkok, 2011.

[8] K. Kodkanon and P. Pinit, "Project based learning: A conceptual model of interdisciplinary team in Science-based technology school," Review of Higher Education and Self-Learning, vol. 6, pp. 171-183, 2013.

[9] C. Golding. (November 2009). On the use of integrating the disciplines: Successful interdisciplinary subject of the Centre for the Study of Higher Education. [Online]. Available: http://www.cshe.unimelb.edu.au/

[10] P. R. Scholtes, B. L. Joiner, and B. J. Streibel, The Team Handbook, 3rd Ed., NJ: Oriel Inc., 2010, pp. 2-1-2-32.

[11] J. M. Palmer, "Planning wheels turn curriculum around," Educational Leadership, vol. 49, iss. 2, p. 57, Oct. 1991

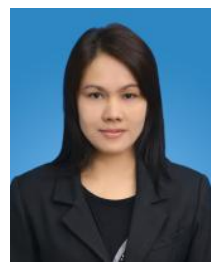

Kanphitcha Kodkanon was born in Thailand on Febuary 7, 1976. She received a bachelor's degree in computer education from Phetchaburi Rajabhat Institute, Thailand in 2003 and master's degree in computer and information Technology from King Mongkut's University of Technology Thonburi, Bangkok, Thailand in 2006. She's currently in a doctoral's degree program in learning innovation and technology, Faculty Industrial Education and Technology, King Mongkut's University of Technology Thonburi, Thailand.

She was a teacher in Ratburi Technical college who teaches computer business about two years. She decided to be lecturer at Bangkok Suvarnabhumi College after gratuage Master's degree. Currently, she is studying doctoral's degree. During this time she published articles on Project based learning: A conceptual model of interdisciplinary teams in Science-based technology school in Review of Higher Education and Self-Learning Journals in 2013. Her interest in an interdisciplinary study. She was membership of Intellectbase International Consortium.

Pichet Pinit is an Asst. Prof. at the Department of Mechanical Technology Education, Faculty Industrial Education and Technology, King Mongkut's University of Technology Thonburi, Thailand. 